\title{
Bone Scan
}

National Cancer Institute

\section{Source}

National Cancer Institute. Bone Scan. NCI Thesaurus. Code C17646.

A nuclear imaging method used to evaluate pathological bone metabolism. 